\title{
A Novel Method for Producing Hydrogen from a Hydrocarbon Liquid Using Microwave In-liquid Plasma
}

\author{
Andi Amijoyo Mochtar ${ }^{1,2}$, Shinfuku Nomura ${ }^{1}$, Shinobu Mukasa ${ }^{1}$, Hiromichi Toyota ${ }^{1}$, Kohji Kawamukai ${ }^{1}$, Kojiro \\ Uegaito $^{1}$ and Fadhli Syahrial ${ }^{1,3}$ \\ 1. Graduate School of Science and Engineering, Ehime University, Ehime 791-8577, Japan \\ 2. Mechanical Engineering Department, Hasanuddin University, Makassar 90245, Indonesia \\ 3. Center for Advanced Research on Energy, University Teknikal Malaysia Melaka, Melaka 76100, Malaysia
}

Received: April 18, 2016 / Accepted: May 04, 2016 / Published: June 30, 2016.

\begin{abstract}
The in-liquid plasma method is a technology in which plasma of several thousand degrees Kelvin is generated within bubbles in a liquid. The purpose of this study is to enhance the hydrogen production rate from waste oils by using in-liquid plasma. Two types of microwave in-liquid plasma apparatus are adopted for hydrogen production. One is a conventional MW (microwave) oven, the other is a microwave generator with a waveguide to apply the in-liquid plasma steam reforming method in $n$-dodecane. The produced gas is $58 \%$ - $90 \%$ hydrogen in these methods. The hydrogen production rate is improved by stabilization of the bubble growth. The gas production rate by plasma feeding steam in $n$-dodecane is 1.4 times higher than that without feeding steam.
\end{abstract}

Key words: In-liquid plasma, hydrogen, microwave, $n$-dodecane, steam reforming, waste oils.

\section{Introduction}

In recent years, energy consumption driven by economic growth has increased dramatically, resulting in degradation to the environment. Therefore, sources of clean energy are becoming increasingly important, in order to protect the environment while maintaining an ample energy supply. Recycling of waste from organic and non-organic materials such as household garbage, waste oil, or plastics can protect the environment by reducing the amount of waste and mitigating the effects of greenhouse gasses. Processing organic and non-organic materials to produce hydrogen gas is a challenging task and has been studied by several researchers [1-3]. The main reason that hydrogen used as fuel is water could be its source, and hydrogen has enormous potential energy per unit mass than any other fuel $[4,5]$.

Corresponding author: Shinfuku Nomura, professor, research fields: heat and mass transfer and in-liquid plasma.
However, hydrogen is not a primary energy source like coal, oil and natural gas, which exist in nature. Rather, it is a secondary energy source that is obtained by processing a primary energy source. Accordingly, a relatively large amount of energy is needed to extract and capture hydrogen [6-8].

Electrolysis of water is the dominant method for manufacturing clean hydrogen. However, since water is an extremely stable material, creating hydrogen from this material would be required tremendous amount of energy. Steam reforming of natural gas is another method that has been commercially used for generating large amounts of hydrogen [9-11]. However, in the steam reforming method, carbon dioxide is released in the final stage of the reaction, so provisions for capturing and storing the $\mathrm{CO}_{2}$ are required $[12,13]$.

One method for extracting and capturing hydrogen from waste materials that has been studied in recent years is the in-liquid plasma process [14-17]. This process can produce hydrogen gas and solidified 
carbon simultaneously without emitting $\mathrm{CO}_{2}$ [18-21]. However, this method is only focus on hydrogen production, which is not as productive as other methods.

Based on the previous study [19], a conventional MW (microwave) oven is used to irradiate at 2.45 $\mathrm{GHz}$ with the ability to circulate the liquid. The power output of the conventional MW oven is 1,260 $\mathrm{W}$ with the magnetron using $750 \mathrm{~W}$ to generate plasma from the total power of MW oven. The microwaves were irradiated and received at the tip of each antennas used to generate plasma inside the bubbles. Six antennas were arranged on a copper plate and placed on a Teflon platform. The device could be applied as a method for continuous production. The configuration includes an effective bubble control plate [19, 22-24] which is selected based on gas production rate.

Additionally, in-liquid plasma steam reforming, which is plasma fed by steam created in hydrocarbon liquid. The power supplied into the vessel reactor for each experiment was varied from $150 \mathrm{~W}$ to $330 \mathrm{~W}$. The microwaves were irradiated through a waveguide in order to prevent loss of energy to the reactor vessel. This method is investigated to accelerate the in-liquid plasma reaction [25-28]. The chemical reactions of discharge in water are used for purification of polluted water [29-31]. In general, the process of discharge in a liquid is a more complicated phenomenon than that in a gas, because discharges in a liquid are unstable and involve phase transitions. When discharge occurs in a liquid, in most cases, bubbles appear. There have been many reports which focused on bubbles in relation to the generation of plasma in a liquid by a variety of methods [32-35]. The behavior of bubbles and plasma generated by high frequency waves and microwaves is observed using a high speed camera [36-39]. Microwave plasma is generated when the electrode is heated to the saturation temperature of $n$-dodecane [33, 40].

The main reason for conducting this study is to compare the hydrogen gas production efficiency of the in-liquid plasma steam reforming method, when using a MW oven and microwave generator with a waveguide as the power supply and $n$-dodecane as the source material. It is expected to offer the most efficient hydrogen production rate with a method that is both simple and environmentally friendly.

\section{Plasma Decomposition Experiment in Conventional MW Oven}

Fig. 1 shows the schematic diagram of a conventional MW oven used in this experiment. Not only can the MW oven easily generate microwaves, but also it becomes commonplace in most households, so there is much anticipation that they will be able to be used as a distributed-type hydrogen generator.

Fig. 2a shows a curve-shaped antenna unit. By applying the curved antenna, the tips of the electrodes are closer to each other and it appears that, the generation of plasma usually occurs near the center of the antenna, which makes the volume of the generated plasma larger. While the reason for this cannot be confirmed at this time, with the curved antenna, since the tips of the electrodes are closer to each other, the electric field breakdown occurs near the center of the antenna, which makes for an increased volume of the generated plasma [38].

Experiments were conducted to investigate the optimal shape of the curve-shaped antenna unit, by changing the length of the antenna $L$ and distance between the tips of the electrodes $d$ and measuring the decomposition gas rate. The length of the antenna is adjusted according to the type of liquid in order to optimize the generation of gas. The length of the antenna is approximately one-fourth of the microwave wave length $(\lambda)[33,41]$. The optimal value of gas rate was $33 \mathrm{~mL} / \mathrm{s}$ when $d$ was $8-12 \mathrm{~mm}$. It was determined that, the optimal antenna shape is comprised of $L=21$ $\mathrm{mm}$ and $d=10 \mathrm{~mm}$. In order to generate plasma, a $550 \mathrm{~mL}$ heat-resistant glass container was placed in a MW oven to be used as a cracking furnace. 


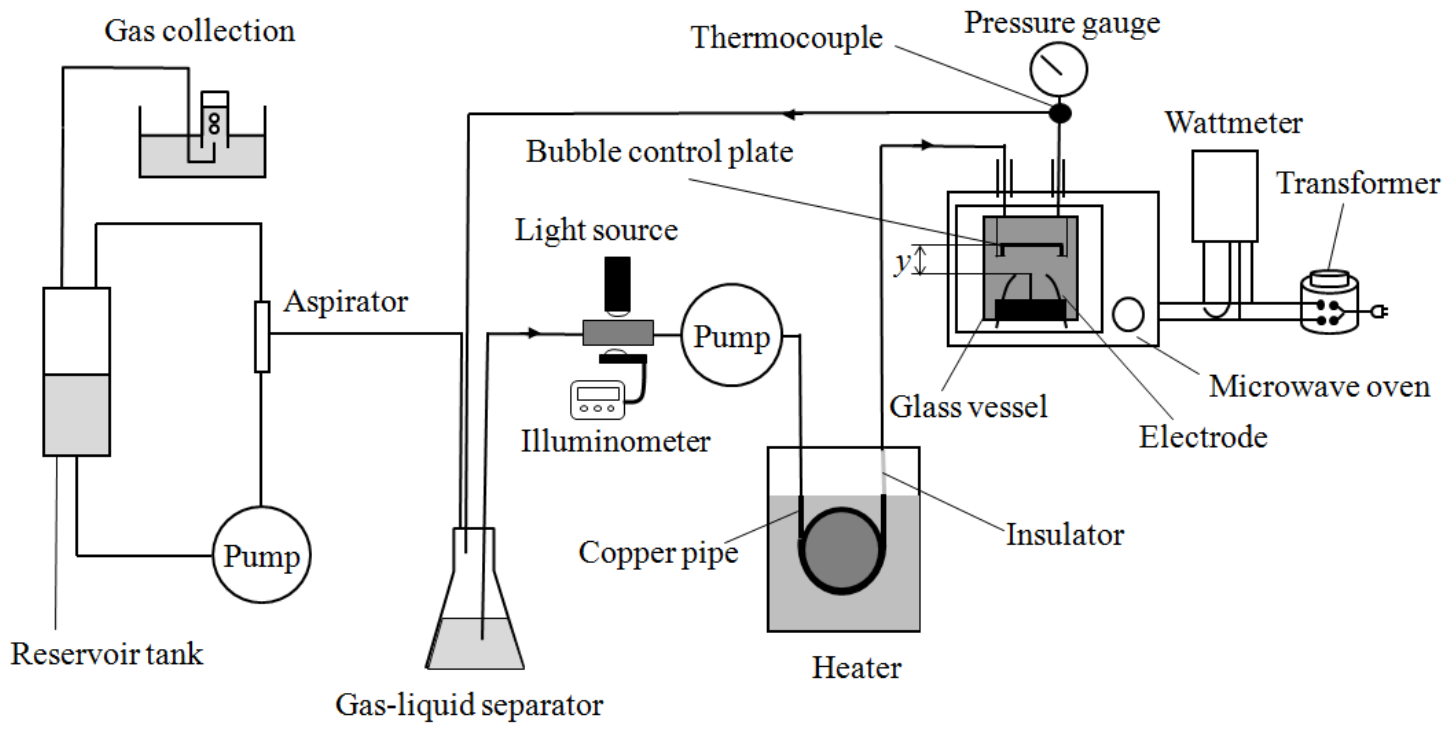

Fig. 1 Experimental setup of hydrogen production using a conventional MW oven.

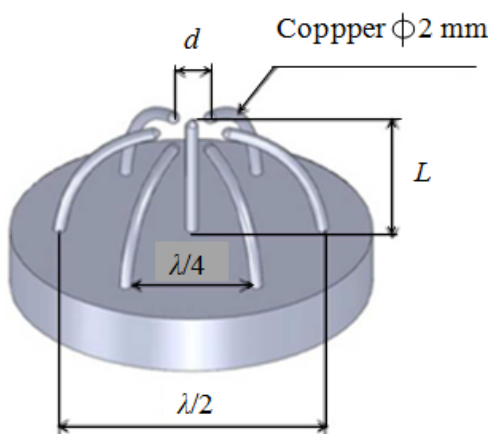

(a) Schematic dimensions of receiving antenna

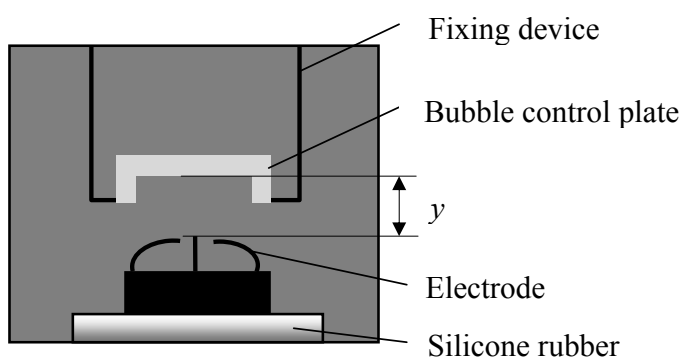

(b) Position of receiving antenna for MW

Fig. 2 Position tip of receiving antenna for microwave.

Fig. $2 \mathrm{~b}$ shows the reactor platform and piping that were made of heat-resistant glass and silicone rubber, to avoid energy absorption from any internal energy reaction. The decomposition furnace was connected to an aspirator. A bubble plate is introduced because use of the plate enhances continues generation of the plasma $[27,36]$.
A pressure gauge was setup from the reactor pipe in order to control the air pressure from the MW oven. Experiments were carried out by depressurizing the reactor using an aspirator. The liquid was circulated by a pump from a reservoir tank. The liquid was heated before being introduced to the reaction field, with the liquid temperature set at $80{ }^{\circ} \mathrm{C}$ in heating case, and at $25{ }^{\circ} \mathrm{C}$ for that without heating. Prior to generating the plasma and collecting gas, the air inside the device was replaced with argon or helium gas, which was then exchanged by the gas generated by the plasma. A thermal conductivity detector was used as the detector for the gas chromatography for analyzing the generated gas. Helium was used as the carrier gas. For the analysis of the gas composition, a gas chromatograph (GC-8A, Shimadzu) equipped with TCD (thermal conductivity detector) was utilized and argon gas was used as a carrier.

With $n$-dodecane, there is ratio of $58 \%-90 \%$ hydrogen in the gas generated by plasma decomposition. Low-grade flammable hydrocarbon gases, such as $\mathrm{C}_{2} \mathrm{H}_{2}, \mathrm{C}_{2} \mathrm{H}_{4}$ and $\mathrm{CH}_{4}$ were also generated. Simultaneously, a large quantity of graphite is synthesized in the vessel.

Fig. 3 shows the effect of the concentration of graphite generated by plasma on the hydrogen yield. 


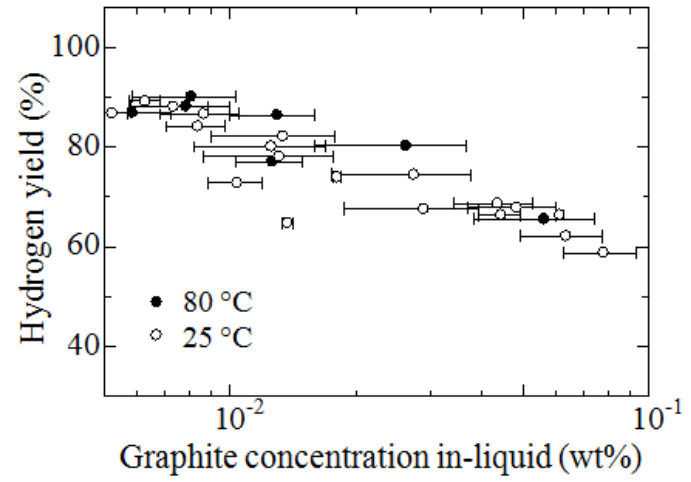

Fig. 3 Hydrogen yield of produced gas.

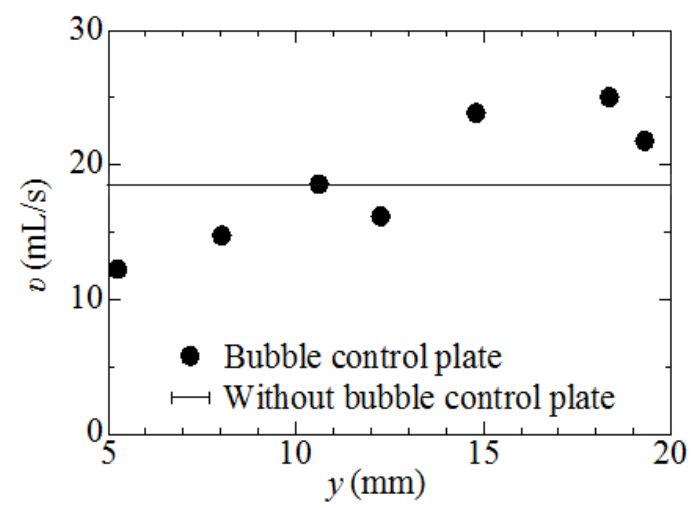

Fig. 4 Effect of the bubble control bubble plate.

The hydrogen concentration in the production gas decreases as the graphite concentration increases in the liquid, with the effect of the liquid temperature becoming negligible. It is highly probable that, a reaction of $\mathrm{H}_{2}$ with the graphite is promoted as graphite density increases leading to the production of the hydrocarbons such as $\mathrm{C}_{2} \mathrm{H}_{2}$.

Fig. 4 shows the experimental results for using a bubble control plate. By using the bubble control plate, the gas production rate can be increased up to 1.3 times. Vapor filled the gap replacing the gas due to the plate, so the gas production rate improves. However, when the gap is increased, the bubble continuously changed in shape in the gap, eventually making the plate ineffective.

\section{In-liquid Plasma Steam Reforming}

Fig. 5 shows the schematic diagram for the steam reforming method, including the gas flow that would be reacted in the vessel reactor. The experiment was conducted under predetermined conditions in which the pressure was at $101.3 \mathrm{kPa}$. The water was heated to approximately $60{ }^{\circ} \mathrm{C}$ and then the steam was supplied into the vessel through the control valve. A reaction container made of a glass pipe of $250 \mathrm{~mL}$ was set up in a wave guide. The microwave irradiation was supplied from a microwave generator to the antenna in the reaction container, with the plasma then generated at the antenna tip where the electric field concentrates.

The antenna was made of a copper material with an outside diameter of $3 \mathrm{~mm}$ and inside diameter of 2 $\mathrm{mm}$. After plasma was generated, the valve was opened and steam began to flow into the reaction container from the water tank through the electrode. The steam temperature was varied by changing the temperature $T$ of the thermostatic bath. The pressure in the reaction container was depressed by an aspirator. The mixture of the gas generated and the water flowing through the aspirator was then separated at a water reservoir tank. Measurement of gas generation rate $v$ and analysis of the compositions of the gas generated was conducted.

Fig. 6 shows the rate gas generation for that with steam and without steam using MW. Fig. 6 also shows that, by using steam, the gas production rate was increased 1.4 times over that without using steam. In steam reforming, the alkaline water temperature was kept constant at $60{ }^{\circ} \mathrm{C}$ in order to produce steam while plasma was generated. The input $P$ power was varied between $100 \mathrm{~W}$ and $325 \mathrm{~W}$. The higher the input power supplied, the greater the rate of generated gas. However, in order to avoid the excessive steam pressure in the reactor, the optimal input power was limited to $325 \mathrm{~W}$.

Fig. 7 shows the gas yield using steam and without steam. At input power of $300 \mathrm{~W}$, the gas yield from decomposition of $n$-dodecane with steam reforming was $\mathrm{H}_{2}(82.0 \%), \mathrm{CO}(6.5 \%), \mathrm{CH}_{4}(1.5 \%), \mathrm{C}_{2} \mathrm{H}_{2}$ $(6.7 \%)$ and $\mathrm{C}_{2} \mathrm{H}_{4}(3.2 \%)$. On the other hand, the gas yield from decomposition of $n$-dodecane without steam reforming was $\mathrm{H}_{2}(82.5 \%), \mathrm{CH}_{4}(3.1 \%), \mathrm{C}_{2} \mathrm{H}_{2}$ 


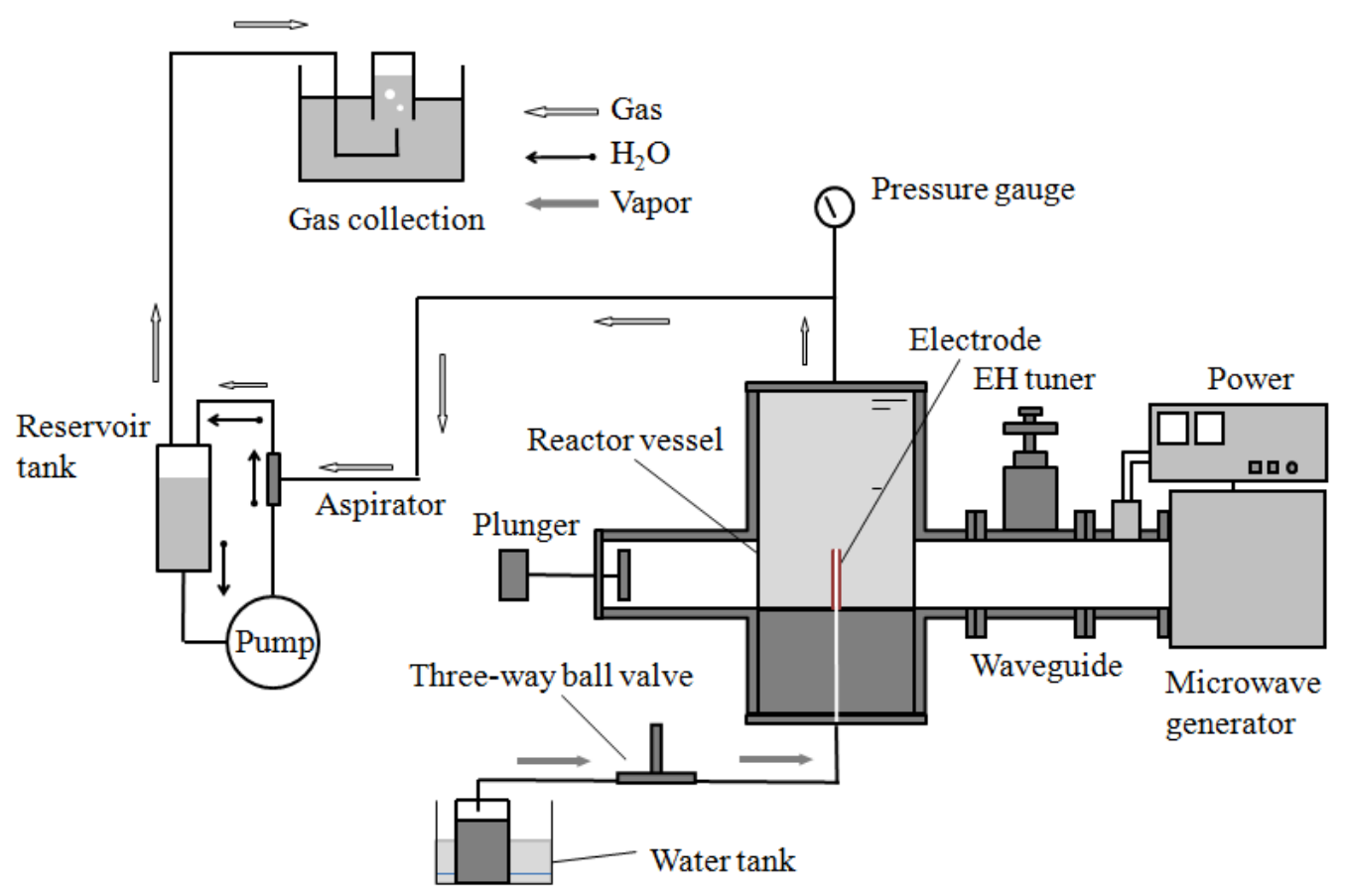

Fig. 5 Schematic of hydrogen production in-liquid plasma using the steam reforming method.

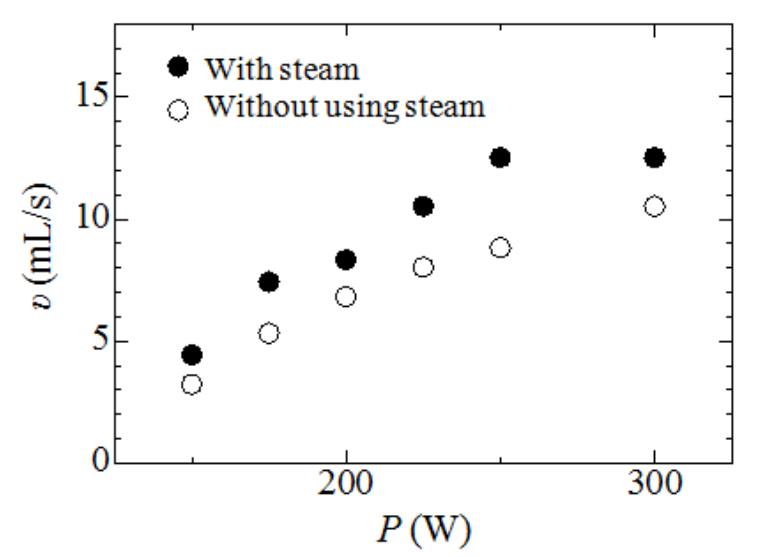

Fig. 6 Rate of generated gas between steam and without steam in the MW reforming method.

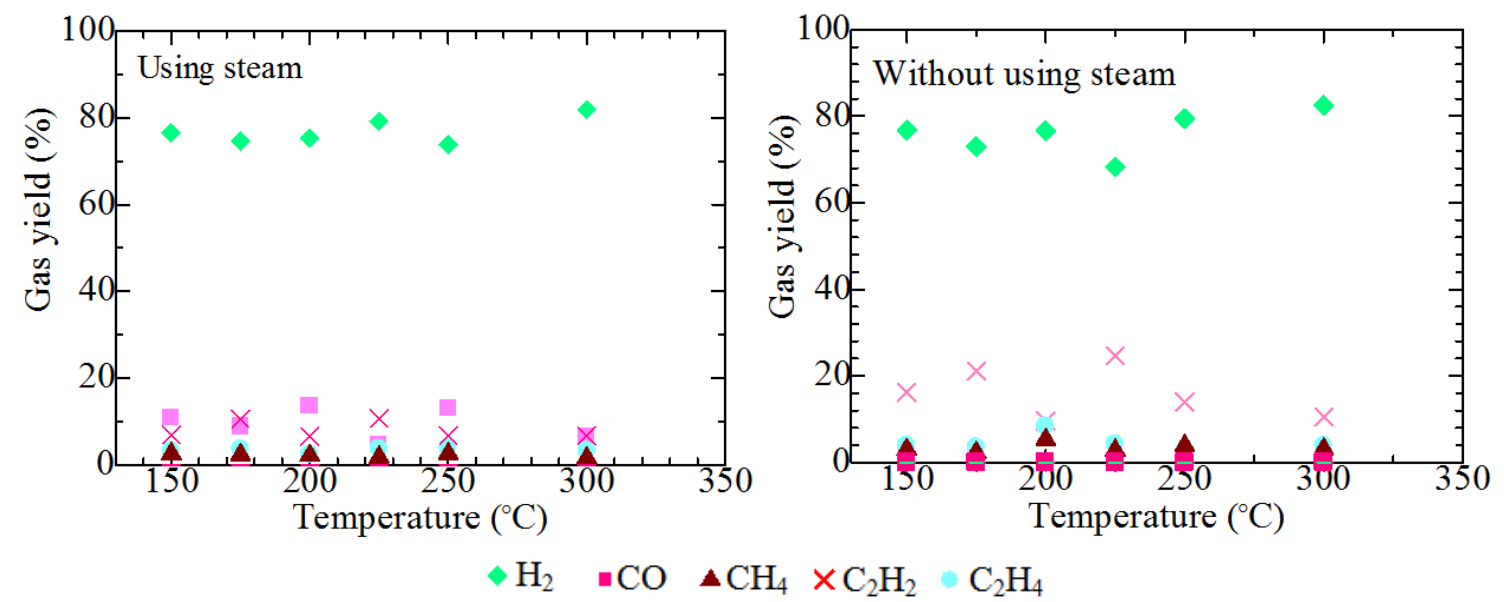

Fig. 7 Gas yield for hydrogen production in MW steam reforming. 
(10.5\%) and $\mathrm{C}_{2} \mathrm{H}_{4}(3.9 \%)$. The obtained results obviously show that, the steam supplied into the process caused production of $\mathrm{CO}$ (carbon monoxide) and reduced other hydrocarbon gases yields. The reduction of hydrocarbon gases yield was suggested due to the reaction of oxygen atoms from steam with carbon atoms from $n$-dodecane for production of carbon monoxide.

\section{Conclusions}

Plasma was generated within the bubble in-liquid. Two types of microwave in-liquid plasma apparatus are adopted for hydrogen production. One is a conventional MW oven, the other is a microwave generator with a waveguide to apply the in-liquid plasma steam reforming method in $n$-dodecane. A conventional MW oven is used to irradiate at $2.45 \mathrm{GHz}$ within liquid. The conventional MW oven has an output of $1,260 \mathrm{~W}$ with only $750 \mathrm{~W}$ being used by the magnetron to generate plasma. Furthermore, in a separated system, $150-330 \mathrm{~W}$ of energy power was used by the steaming reforming method to generate plasma in the vessel reactor. For the experimental results of the MW oven, the hydrogen proportion of the generated gas was affected by the graphite concentration. Hydrogen was dominant in the gas produced, with the ratio around $58 \%-90 \%$ of the total gas. By using a bubble control plate, the gas production rate could be increased up to 1.3 times. The gas production rate using steam reforming could be increased up to 1.4 times over that without using steam reforming. This indicates that, steam reforming method was effective in producing hydrogen gas since the rate of hydrogen gas production is higher than that of using a conventional MW oven.

\section{Acknowledgments}

This work was partially funded and supported by the Iwatani Naoji Foundation.

\section{References}

[1] Das, D., and Veziroä, T. N. 2001. "Hydrogen Production by Biological Processes: A Survey of Literature." International Journal of Hydrogen Energy 26 (1): 13-28.

[2] Cheng, S., and Hamelers, H. V. M. 2008. "Critical Review Microbial Electrolysis Cells for High Yield Hydrogen Gas Production from Organic Matter." Environmental Science \& Technology 42 (23): 8630-40.

[3] Oh, S., and Logan, B. E. 2003. "The Relative Effectiveness of $\mathrm{pH}$ Control and Heat Treatment for Enhancing Biohydrogen Gas Production." Environmental Science \& Technology 37 (22): 5186-90.

[4] Hrycak, B., Czylkowski, D., Miotk, R., Dors, M., and Jasinski, M. 2014. "Science Direct Application of Atmospheric Pressure Microwave Plasma Source for Hydrogen Production from Ethanol." International Journal of Hydrogen Energy 39 (26): 14184-90.

[5] Abbas, H. F., and Wan Daud, W. M. A. 2010. "Hydrogen Production by Methane Decomposition: A Review." International Journal of Hydrogen Energy 35 (3): 1160-90.

[6] Mollersten, K., Yan, J., and Moreira, J. R. 2003. "Potential Market Niches for Biomass Energy with $\mathrm{CO}_{2}$ Capture and Storage-Opportunities for Energy Supply with Negative $\mathrm{CO}_{2}$ Emissions." Biomass and Bioenergy 25 (3): 273-85.

[7] Moriarty, P., and Honnery, D. 2009. "Hydrogen's Role in an Uncertain Energy Future." International Journal of Hydrogen Energy 34 (1): 31-9.

[8] Miyake, J., Miyake, M., and Asada, Y. 1999. "Biotechnological Hydrogen Production: Research for Efficient Light Energy Conversion." Journal of Biotechnology 70 (1): 89-101.

[9] Arauzo, J., Bimbela, F., Oliva, M., Ruiz, J., and Garc1, L. 2007. "Hydrogen Production by Catalytic Steam Reforming of Acetic Acid, a Model Compound of Biomass Pyrolysis Liquids." Journal of Analytical and Applied Pyrolysis 79 (1): 112-20.

[10] Holladay, J. D., Hu, J., King, D. L., and Wang, Y. 2009. "An Overview of Hydrogen Production Technologies." Catalysis Today 139 (4): 244-60.

[11] Bundaleska, N., Tsyganov, D., Tatarova, E., Dias, F. M., and Ferreira, C. M. 2014. "Steam Reforming of Ethanol into Hydrogen-Rich Gas Using Microwave Ar/Water 'Tornado'-Type Plasma." International Journal of Hydrogen Energy 39 (11): 5663-70.

[12] Abanades, J. C., Abanades, J. C., Rubin, E. S., and Anthony, E. J. 2004. "Sorbent Cost and Performance in $\mathrm{CO}_{2}$ Capture Systems." Industrial \& Engineering Chemistry Research 43 (13): 3462-6.

[13] Bohn, C. D., Mu, C. R., Cleeton, J. P., Hayhurst, A. N., Davidson, J. F., Scott, S. A., and Dennis, J. S. 2008. "Production of Very Pure Hydrogen with Simultaneous 


\section{A Novel Method for Producing Hydrogen from a Hydrocarbon Liquid Using Microwave In-liquid Plasma}

Capture of Carbon Dioxide Using the Redox Reactions of Iron Oxides in Packed Beds." Industrial \& Engineering Chemistry Research 47 (20): 7623-30.

[14] Hallenbeck, P. C., and Centre-ville, S. 2009. "Fermentative Hydrogen Production: Principles, Progress, and Prognosis." International Journal of Hydrogen Energy 34 (17): 7379-89.

[15] Balat, H., and Kırtay, E. 2010. "Hydrogen from Biomass-Present Scenario and Future Prospects." International Journal of Hydrogen Energy 35 (14): 7416-26.

[16] Logan, B. E., and Rabaey, K. 2012. "Conversion of Wastes into Bioelectricity and Chemicals by Using Microbial Electrochemical Technologies." Science 337 (6095): 686-90.

[17] Nomura, S., Toyota, H., Tawara, M., Yamashita, H., and Matsumoto, K. 2006. "Fuel Gas Production by Microwave Plasma in Liquid." Applied Physics Letters 88 (23): 231502.

[18] Cormos, C. 2009. "Assessment of Hydrogen and Electricity Co-production Schemes Based on Gasification Process with Carbon Capture and Storage." International Journal of Hydrogen Energy 34 (15): 6065-77.

[19] Nomura, S., Toyota, H., Mukasa, S., Yamashita, H., Maehara, T., and Kawashima, A. 2009. "Production of Hydrogen in a Conventional Microwave Oven." Journal of Applied Physics 106 (7): 073306.

[20] Rahim, I., Nomura, S., Mukasa, S., and Toyota, H. 2015. "Decomposition of Methane Hydrate for Hydrogen Production Using Microwave and Radio Frequency In-liquid Plasma Methods." Applied Thermal Engineering 90 (November): 120-6.

[21] Putra, A. E. E., Nomura, S., Mukasa, S., and Toyota, H. 2012. "Hydrogen Production by Radio Frequency Plasma Stimulation in Methane Hydrate at Atmospheric Pressure." International Journal of Hydrogen Energy 37 (21): 16000-5.

[22] Maehara, T., Honda, S., Inokuchi, C., Kuramoto, M., Mukasa, S., Toyota, H., Nomura, S., and Kawashima, A. 2011. "Influence of Conductivity on the Generation of a Radio Frequency Plasma Surrounded by Bubbles in Water." Plasma Sources Science and Technology 20 (3): 034016.

[23] Hattori, Y., Mukasa, S., Toyota, H., Inoue, T., and Nomura, S. 2011. "Continuous Synthesis of Magnesium-Hydroxide, Zinc-Oxide, and Silver Nanoparticles by Microwave Plasma in Water." Materials Chemistry and Physics 131 (1-2): 425-30.

[24] Palo, D. R. R., Dagle, A., and Holladay, J. D. 2007. "Methanol Steam Reforming for Hydrogen Production." Chemical Reviews 107 (10): 3992-4021.

[25] Nomura, S., Toyota, H., Mukasa, S., Yamashita, H.,
Maehara, T., and Kuramoto, M. 2006. "Microwave Plasma in Hydrocarbon Liquids." Applied Physics Letters 88 (21): 114-6

[26] Maehara, T., Toyota, H., Kuramoto, M., Iwamae, A., Tadokoro, A., Mukasa, S., Yamashita, H., Kawashima, A., and Nomura, S. 2006. "Radio Frequency Plasma in Water." Japanese Journal of Applied Physics 45 (11R): 8864-8.

[27] Hattori, Y., Mukasa, S., Toyota, H., Inoue, T., and Nomura, S. 2011. "Synthesis of Zinc and Zinc Oxide Nanoparticles from Zinc Electrode Using Plasma In-liquid." Materials Letters 65 (2): 188-90.

[28] Nomura, S., Toyota, H., Mukasa, S., Takahashi, Y., Maehara, T., Kawashima, A., and Yamashita, H. 2008. "Discharge Characteristics of Microwave and High-Frequency In-liquid Plasma in Water." Applied Physics Express 1 (4): 046002.

[29] Cetinkaya, E., Dincer, I., and Naterer, G. F. 2011. "Life Cycle Assessment of Various Hydrogen Production Methods." International Journal of Hydrogen Energy 37 (3): 2071-80.

[30] Hattori, Y., Mukasa, S., Toyota, H., and Nomura, S. 2013. "Electrical Breakdown of Microwave Plasma in Water." Journal of Applied Physics 13 (6): 1050-4.

[31] Wang, Q., Spasova, B., Hessel, V., and Kolb, G. 2015. "Methane Reforming in a Small-Scaled Plasma Reactor Industrial Application of a Plasma Process from the Viewpoint of the Environmental Profile." Chemical Engineering Journal 262 (February): 766-74.

[32] Syahrial, F., Mukasa, S., Toyota, H., and Okamoto, K. 2014. "Hydrogen Production from Glucose and Cellulose Using Radio Frequency In-liquid Plasma and Ultrasonic Irradiation." Journal of Japanese Institue of Energy 93 (11): 1207-12

[33] Toyota, H., Mukasa, S., and Nomura, S. 2013. "A Practical Electrode for Microwave Plasma Processes." International Journal of Materials Science and Applications 2 (3): 83-8.

[34] Hattori, Y., Mukasa, S., Nomura, S., and Toyota, H. 2010. "Optimization and Analysis of Shape of Coaxial Electrode for Microwave Plasma in Water." Journal of Applied Physics 107 (6): 063305.

[35] Shih, K. Y., and Locke, B. R. 2009. "Effects of Electrode Protrusion Length, Pre-existing Bubbles, Solution Conductivity and Temperature, on Liquid Phase Pulsed Electrical Discharge." Plasma Process Polymer 6 (11): 729-40.

[36] Hattori, Y., Nomura, S., Mukasa, S., Toyota, H., and Inoue, T. 2013. "Synthesis of Tungsten Trioxide Nanoparticles by Microwave Plasma in Liquid and Analysis of Physical Properties." Journal of Alloys and Compounds 560 (May): 105-10. 
[37] Mukasa, S., Nomura, S., Toyota, H., Maehara, T., Abe, F., and Kawashima, A. 2009. "Temperature Distributions of Radio-Rrequency Plasma in Water by Spectroscopic Analysis." Journal of Applied Physics 106 (11): 9-10.

[38] Nomura, S., Mukasa, S., Toyota, H., Miyake, H., Yamashita, H., Maehara, T., Kawashima, A., and Abe, F. 2011. "Characteristics of In-liquid Plasma in Water under Higher Pressure than Atmospheric Pressure." Plasma Sources Science and Technology 20 (3): 034012.

[39] Mukasa, S., Nomura, S., Toyota, H., Maehara, T., and
Yamashita, H. 2011. "Internal Conditions of a Bubble Containing Radio-Frequency Plasma in Water." Plasma Sources Science and Technology 20 (3): 034020.

[40] Mukasa, S., Nomura, S., and Toyota, H. 2004. "Measurement of Temperature in Sonoplasma." Japanese Journal of Applied Physics 43 (5B): 2833-7.

[41] Nomura, S., Nakagawa, M., Mukasa, S., Toyota, H., Murakami, K., and Kobayashi, R. 2005. "Ultrasonic Heat Transfer Enhancement with Obstacle in Front of Heating Surface." Japanese Journal of Applied Physics 44 (6B): 4674-7. 